Cómo citar este trabajo: Luque Revuelto, R. M., \& Sandoval Estrada, M. A. (2018). La pervivencia de la olivicultural tradicional en el valle de Huasco (Atacama, Chile). Boletín de la Asociación de Geógrafos Españoles, 77, 335-367. doi: http://dx.doi.org/10.21138/bage.2544

\title{
La pervivencia de la olivicultura tradicional en el valle de Huasco (Atacama, Chile)
}

\author{
The survival of the traditional olive growing \\ in the valley of Huasco (Atacama, Chile)
}

\author{
Ricardo Manuel Luque Revuelto \\ ch1lurer@uco.es \\ Departamento de Ciencias del Territorio \\ Universidad de Córdoba (España) \\ Marco Antonio Sandoval Estrada \\ masandov@udec.cl \\ Departamento de Suelos y Recursos Naturales \\ Universidad de Concepción (Chile)
}

\section{Resumen}

La explotación del olivar en la región de Atacama es una actividad agraria que se remonta a la llegada de los primeros españoles en el siglo XVI. Actualmente se encuentra amenazada por un problema de salinización de suelos. La escasez de agua, la aparición de enfermedades del olivo, la competencia de las actividades extractivas o la pérdida de vínculos afectivos de la población con el territorio agravan la situación presente. Problemas estos, que de no resolverse, comprometerían gravemente, no solo la olivicultura tradicional del valle, sino las ancestrales sociedades agrarias que la sostienen.

Palabras clave: olivar; salinización de suelos; Huasco; Atacama; Chile. 


\begin{abstract}
The development of the olive grove in the Atacama region is an agrarian activity that goes back to the arrival of the first Spaniards in the XVIth century. At present it is at a standstill due to a problem of salinización of soils. The water scarcity, the appearance of illnesses of the olive tree, the competition of the extractive activities or the loss of affective ties of the population with the territory, aggravate the present situation. These problems, if not solved, would seriously compromise, not only the traditional olive growing of the valley, but also the ancestral agrarian societies that support it.
\end{abstract}

Key words: olive grove; soil salinization; Huasco; Atacama; Chile.

\title{
1 Introducción
}

Sobre las terrazas del valle bajo del río Huasco se viene realizando un ancestral aprovechamiento agrario relacionado con la explotación del olivo, que a vista satelital y a modo de delgada línea verde destaca sobre un paisaje dunar y desértico en la región de Atacama.

Actualmente la pervivencia de esta agricultura tradicional se encuentra en una difícil encrucijada, en la que no solo están en peligro las centenarias matas de olivar o la envejecida población agraria que las mantiene, sino una inestimable cultura que ha sabido a lo largo de los siglos mantener un primoroso equilibrio entre un medio extremadamente frágil y unos aprovechamientos agrarios que han permitido de forma sostenible la continuidad de unas sociedades agrarias ancestrales.

El deterioro de los suelos, la escasez de agua, la aparición de enfermedades del olivo, la competencia de las actividades extractivas y energéticas, la perdida de activos agrarios, la desarticulación del poblamiento o la pérdida de vínculos afectivos de la población con el territorio parecen conjurarse para comprometer seriamente estos paisajes agrarios y culturales.

Con todo, diferentes iniciativas públicas, proyectos de responsabilidad empresarial y propuestas ciudadanas ligadas a la existencia de este y de otros recursos, y una diversificación de las actividades productivas hacen albergar esperanzas acerca de esta agricultura tradicional con miras a la construcción de un territorio ambiental, social y económicamente sostenible.

\section{Los componentes naturales}

El valle del río Huasco, denominado como el Jardín de Atacama, atraviesa en sentido paralelo la distancia existente entre la Cordillera de Los Andes y el océano Pacífico. El río Huasco es el único curso fluvial con caudal hasta su desembocadura en Atacama, y constituye, no solo el soporte del ecosistema desértico más al norte de Chile, sino también un recurso por el que pugnan las poblaciones asentadas en sus orillas, al mismo tiempo que las actividades agrícolas, pesqueras, mineras e industriales. Su cuenca hidrográfica se extiende entre los paralelos $28^{\circ}, 30^{\prime}$ y $29^{\circ}, 40^{\prime}$ de 
latitud sur, con una extensión de 9850 km². El curso del río transcurre a lo largo de 230 kilómetros, surcando la parte central de una hoya enmarcada en su nacimiento en el este por el cerro El Potro y la cordillera de Doña Ana, al norte por las montañas de Pulido, y al sur por un ramal de dicha cordillera de Doña Ana. En la Junta del Carmen el río Huasco se divide en dos afluentes principales: los ríos El Carmen y El Tránsito, los cuales se bifurcan a su vez en distintos afluentes y corrientes que se alimentan en la cordillera de Los Andes. Su cuenca media y baja está regulada por el embalse de Santa Juana, que desde 1995 y con una capacidad de 163 hectómetros cúbicos abastece de forma regular a las poblaciones y los cultivos aguas abajo.

\section{Figura 1. Vista satelital del valle bajo del río Huasco}

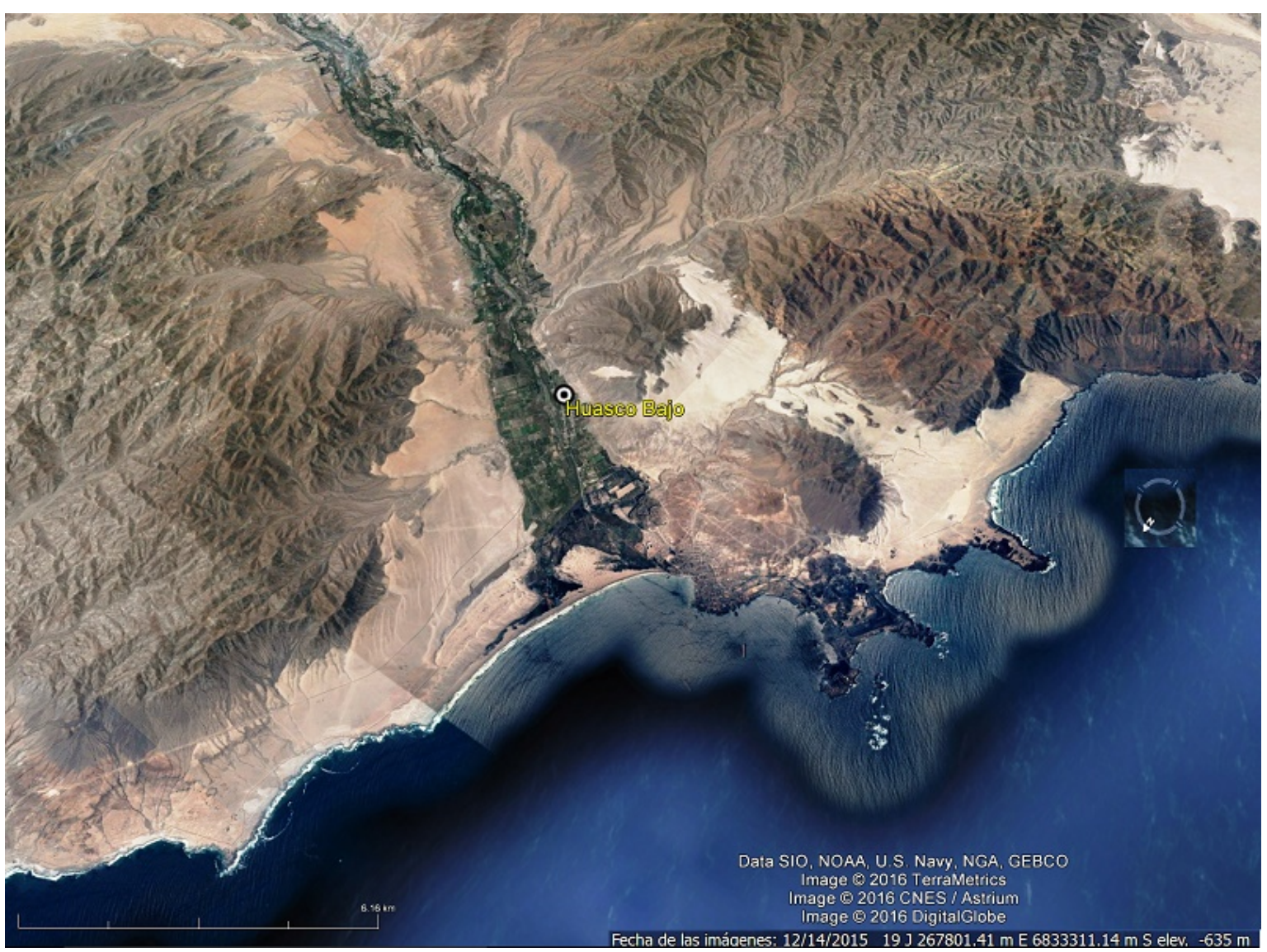

Fuente: imagen extraída de Google Earth (14 de diciembre de 2015)

La comuna de Huasco se localiza al oeste de la provincia y a su vez está conformada por diferentes localidades, siendo las más pobladas la propia Huasco, Huasco Bajo, Canto de Agua y Carrizal Bajo. La comuna de Huasco junto a las de Vallenar, Freirina y Alto del Carmen conforma la Provincia de Huasco al sur de la III Región de Atacama. La provincia tiene una superficie de 19.066 km² y posee una población de 73952 habitantes (INE, 2012), con tan solo una densidad de 3,87 habitantes por $\mathrm{km}^{2}$. Este dato corrobora los grandes desequilibrios que existen en la distribución de la población chilena, siendo la media nacional de 23,01 habitantes por $\mathrm{km}^{2}$, y ello sin perder de 
vista que aproximadamente el 38 \% se concentra en el área metropolitana de Santiago. La capital provincial reside en la ciudad de Vallenar.

Figura 2. Mapa geológico del valle bajo de Huasco
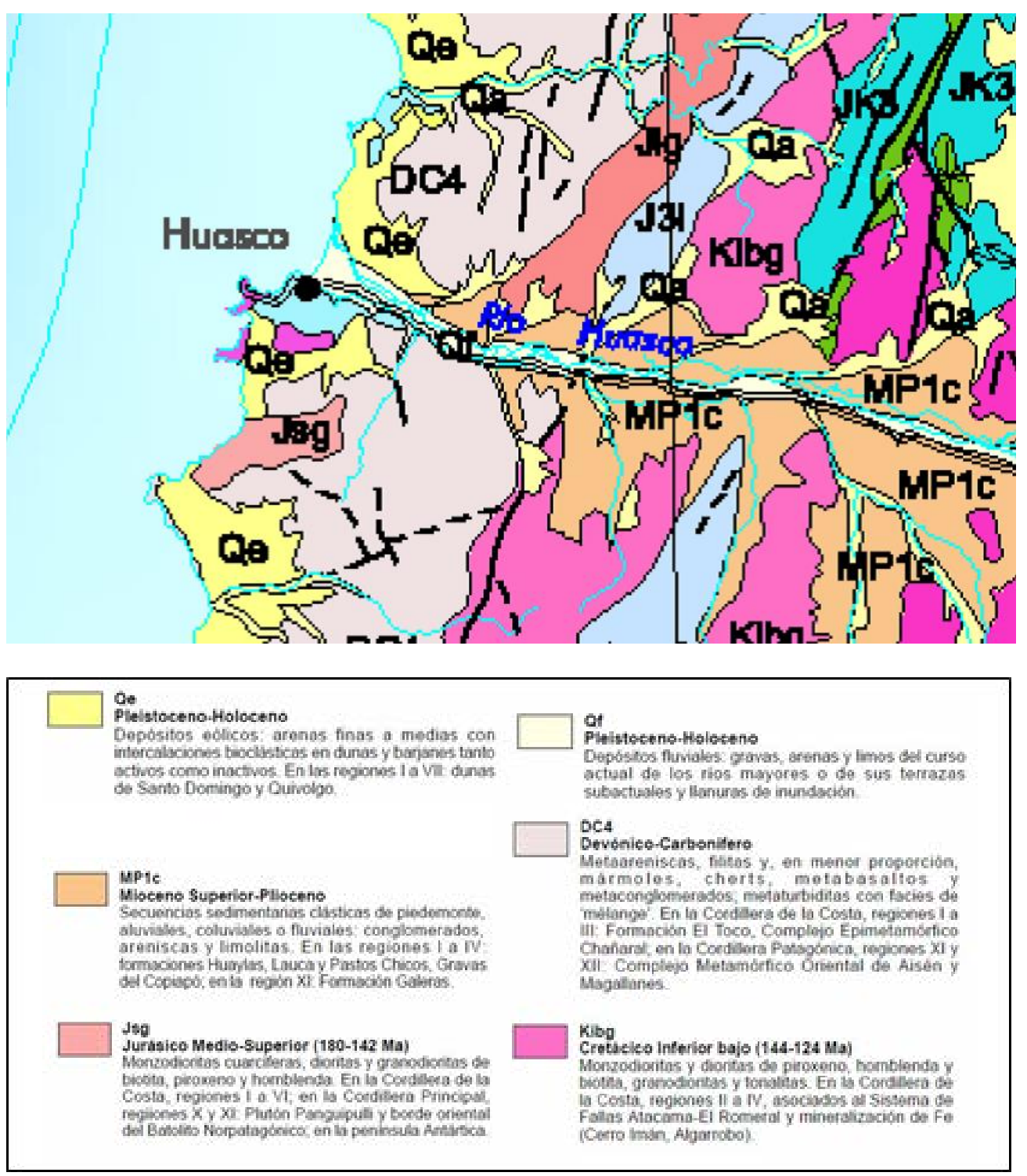

Fuente: Servicio Nacional de Geología y Minería de Chile (2003)

Atacama se encuentra bajo la influencia del Anticiclón del Pacífico, que ocasiona los vientos predominantes del Sur y Suroeste y minimiza las precipitaciones. La comuna de Huasco se encuadra dentro de un clima desértico costero con nubosidad BWn (según la clasificación climática de Trewartha) o árido frío BWk (según la de climática de Köppen), con temperaturas medias anuales inferiores a $18{ }^{\circ} \mathrm{C}$. Las precipitaciones son muy escasas y se concentran en invierno, no superando los $100 \mathrm{~mm}$ anuales, si bien, cuando revisten un carácter torrencial pueden alcanzar esta media en pocos días. La nubosidad -matinal sobre todo- es muy abundante. Estas nieblas o camanchacas arrastran la humedad del océano alimentando una vegetación somera de arbustos 
xerófitos. La franja litoral de este clima es relativamente estrecha y no sobrepasa los 50 kilómetros en la parte más extensa.

El sistema orogénico andino y su evolución geológica han definido una serie de unidades de relieve principales en Atacama que son de este a oeste: la Cordillera Principal, la Depresión de los Salares, la Precordillera, el Valle Longitudinal y la Cordillera de la Costa con la plataforma litoral. En esta última unidad de relieve se localiza la comuna de Huasco, una cordillera litoral, paralela al océano Pacífico, con cerros de moderada altura que alcanzan hasta los 1000 metros.

El factor climático, junto a los procesos geológicos y tectónicos ha configurado una morfología peculiar en la región (Riveros \& Riquelme, 2009). La escasa vegetación natural y la ausencia de precipitaciones convierten a las diferentes formas de meteorización y erosión en los principales agentes modeladores del territorio. El viento juega un papel muy importante en la formación del paisaje, particularmente en la formación de dunas litorales -como se aprecia en la Figura 1-, aunque la formación más abundante es el desierto rocoso, con suaves cerros y extensas llanuras de escombros y detritus surcadas cuencas endorreicas o por valles o quebradas -cursos de agua de poca madurez, intermitentes y ocasionalmente torrenciales-.

Una atenta mirada al mapa geológico (Figura 2) nos permite diferenciar las secuencias sedimentarias litorales y fluviales que cubren los descarnados relieves devónicos, jurásicos y cretácicos que a modo de bandas paralelas se jalonan desde la costa hacia el interior. Los depósitos eólicos de arenas finas forman dunas activas que desde la costa y hacia el interior enmarcan la desembocadura del río Huasco y amenazan invadir el fértil valle y su marisma al mismo tiempo que la localidad de Huasco Bajo.

Las secuencias sedimentarias miocenas y pliocenas clásticas, aluviales o coluviales forman una segunda banda sin solución de continuidad con la anterior y actúan como transición o piedemontes entre los cerros paleozoicos, mesozoicos y los depósitos fluviales de gravas, arenas y limos, que en terrazas y llanuras de inundación constituyen el soporte de las explotaciones de olivar que jalonan el río Huasco prácticamente hasta su desembocadura. Estos depósitos de materiales sedimentarios permiten también la existencia de importantes acuíferos, cuyas aguas se saturan con las sales solubles de los sedimentos y al aflorar a la superficie lo hacen con una elevada salinidad que perjudica los cultivos del curso inferior del río (Díaz, Avilés, Nogueira \& Valdés, 1957).

En el litoral destaca la existencia de una península (véase la Figura 1) en donde se localiza la central termoeléctrica de Guacolda y que con anterioridad a 1960 constituía una isla, que fue unida al continente con el fin de crear una bahía artificial en donde pudiesen atracar los buques que surten de carbón a la central. Depósitos de arenas de origen marino y continental tapizan la línea del litoral, formando playas y dunas vivas que avanzan hacia el interior en la misma desembocadura del río Huasco y al sudoeste de Huasco Bajo, amenazando con sepultar el fértil valle y la misma 
localidad. Los intensos procesos de meteorización, favorecidos por las condiciones climáticas, han permitido la formación de estos depósitos que son empujados a gran velocidad por los vientos alisios y la corriente del Perú, procedente del Pacífico Sur, y se adentran a varios kilómetros en el continente, a falta de vegetación que detenga el avance de las dunas en los descarnados relieves litorales.

\section{Los componentes humanos}

La comuna de Huasco ha experimentado una evolución demográfica positiva, desde los 7015 habitantes censados en 1982, hasta los 10263 alcanzando en 2015. Es decir, ha aumentado un 46 por ciento más desde la primera fecha, con un dinamismo superior a las demás comunas, e incluso mayor que la capital provincial, que solo lo hacía un 24 por ciento, pese a que esta reúna ya más de cincuenta mil habitantes. La razón estriba en el hecho de que a la población local se ha incorporado un numeroso contingente de trabajadores empleados en la minería, en la planta de hierro, en el puerto y en las centrales termoeléctricas de ENDESA y de Guacolda.

Por lo que respecta a la dinámica natural de la población se aprecia una coincidencia entre los valores de la comuna y los regionales, tanto en los valores absolutos como en su evolución, si bien existen ligeras diferencias entre ellas y más acusadas con respecto a los valores nacionales. Así la tasa de natalidad de Huasco en la década de 2000-2010 se situaba en el 19,1 por mil, ligeramente superior a la de la región $(18,1)$ y más distanciada del total nacional $(14,7)$ (Ministerio de Desarrollo Social, 2014). El dinamismo demográfico de la región es, por tanto, considerable y este hecho se refuerza si tenemos en consideración la tasa global de fecundidad, que en Atacama alcanzaba el promedio de 2,16 hijos por mujer en 2013 (Comité Nacional de Estadísticas Vitales, 2015), la segunda más alta del país $(1,79)$, después de la región de Tarapacá $(2,36)$.

La menor desaceleración demográfica de Huasco y su región explica que las tasas de mortalidad (4,4 por mil y 4,7 por mil, respectivamente) sean inferiores al conjunto nacional (5,4 por mil) (Ministerio de Desarrollo Social, 2014). Sin embargo, la esperanza de vida al nacer resulta menor en la comuna que en el conjunto del país, tanto para los varones $(72,6)$ como para las mujeres $(78,2)$, siendo aquella de 75,5 para los varones y de 81,5 para las mujeres.

La pirámide de población representada (Figura 3) nos muestra una población estacionaria, con el grueso de los efectivos formado por adultos (69\%), seguida de los jóvenes (18\%) y los ancianos (13\%). De ello resulta una Tasa de Dependencia baja: 46\%. El Índice Global de Masculinidad

1 La planta pelletizadora de hierro de la Compañía de Acero del Pacífico (1978), el Puerto Mecanizado Guacolda y la termoeléctrica ENDESA (1962-1965), la construcción del Puerto Mecanizado Guacolda II (1972-1977), y la termoeléctrica de Eléctrica Guacolda (1992-2015) han supuesto desde un punto de vista demográfico la llegada de importantes contingentes de población flotante de hasta 2000 o 3000 trabajadores que se retiran una vez que terminan las faenas las respectivas empresas contratistas. 
$(102,70)$ muestra una mayor proporción de varones, asimismo lo es también en las tres edades: jóvenes, adultos, e incluso ancianos. Sin duda, la menor relación de mujeres se debe a la existencia de actividades extractivas y energéticas en la región que requieren una mayor demanda de empleo para los varones, muchos de los cuales no llegan con sus familias, dadas la menor disponibilidad de expectativas y acceso a los servicios que presenta esta región de Atacama.

Figura 3. Pirámide de población de Huasco, año 2015

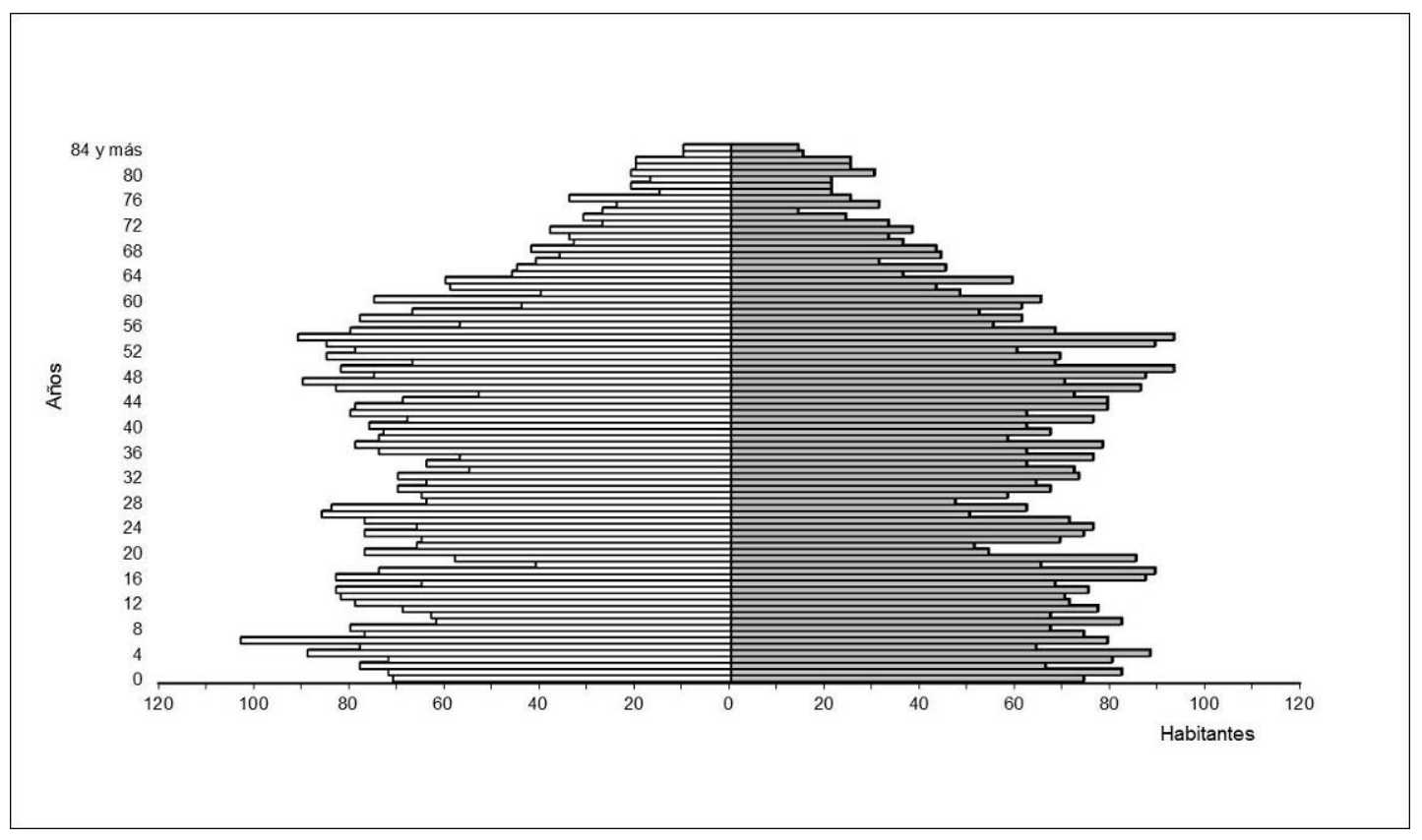

Fuente: elaboración propia a partir del INE (2015)

En efecto, la construcción de la central termoeléctrica en diferentes fases: 1995-1996, 2009_ 2010 y 2012-2015, periodo en el que se ha puesto en funcionamiento la unidad 5 de Guacolda, ha supuesto el aporte de contingentes de trabajadores cualificados de otras regiones, muchos de ellos de forma temporal, aunque también bastantes definitivos, por la creación de más de un centenar de empleos directos en la planta. En cambio, en otras comunas como en los totales regionales, los saldos migratorios han sido negativos, con valores de hasta un -11,3 por mil (19771982), y con excepción del periodo 1987-1992 en que hubo una migración neta positiva de un 4,2 por mil por el desarrollo que alcanzó el sector frutícola (INE, 2007). En el último censo de población (2002) la región de Atacama continuaba siendo expulsora de población con una tasa de migración neta de -5,2 por mil. El perfil de los migrantes, tanto intrarregionales como interregionales, en las comunas de Atacama es el de un varón joven, entre 20 y 34 años y un nivel de educación intermedio recibido en Centros de Formación Técnica e Institutos Profesionales (INE, 2008).

Por lo que respecta al poblamiento de la comuna de Huasco podemos afirmar que se integra espacial y funcionalmente dentro de la región de Atacama y, al igual que ella, presenta unas 
características comunes a esta zona norte del país y al conjunto de la nación. En primer lugar hay que señalar, como característica más notable, el elevado grado de concentración de la población en núcleos urbanos, ${ }^{2}$ siendo ya de por sí Chile uno de los países con mayor concentración de población urbana de América Latina, con una tasa de $86,6 \%$ y solo superada por Argentina, Uruguay y Venezuela (CELADE, 2005). La comuna de Huasco aglutina su población en la localidad de Huasco. ${ }^{3}$ A ella se fueron anexando poblados o barriadas de trabajadores provisionales, como la de ENDESA, CAP en las proximidades de la isla Guacolda, la población Huasco II y III. A unos kilómetros se localiza el pequeño poblado de Huasco Bajo, siguiendo la ruta C-46 que une Vallenar con Huasco, en la ribera sur del río Huasco. Cabe mencionar también la existencia de los antiguos poblados de mineros de Canto del Agua y Carrizal Bajo, que actualmente se encuentran prácticamente despoblados, pero que impulsados por las explotaciones mineras de cobre llegaron a albergar importantes contingentes de población. Así Carrizal Alto alcanzó alrededor de 8000 habitantes en el segundo tercio del siglo XIX, llegando a albergar una de las mineras de cobre más grandes de Chile, incluso con conexión ferroviaria y un puerto de embarque de mineral. Sin embargo, el agotamiento de las minas y el auge del salitre redujo a finales de siglo la población a 1652 habitantes (Solano, 1899) y en el presente se encuentra prácticamente deshabitado.

La segunda característica destacable del poblamiento es la práctica ausencia del hábitat diseminado, hecho que se corresponde con las particularidades del medio físico que limita la disponibilidad de agua y tierras fértiles al valle estricto del río Huasco. Si encontramos algunas casas dispersas es precisamente entre las plantaciones de olivos que tapizan dicho valle. Así pues la población que reside en núcleos menores de 2.000 habitantes y en diseminado alcanza un 18,9 $\%$, frente a un $81,1 \%$ que es urbana (MINVU, 2009), valores que se encuentran por debajo de las medias nacionales, pero que indudablemente señalan índices muy altos de concentración de la población.

Otra característica importante del poblamiento es su peculiar distribución, que sigue unos determinados ejes o corredores, tanto longitudinales como transversales por los que discurren las principales comunicaciones que enlazan los núcleos de población principales, situados a modo de lugares centrales. El valle longitudinal y el litoral, separados por la cordillera de la costa, ambos paralelos a los Andes, son los principales ejes de poblamiento, que a su vez cruzan con una sucesión de valles fluviales perpendiculares a dichas unidades, y que tienen su cabecera en las cumbres de los Andes. Es precisamente en dichas intercesiones donde se ubican los principales

2 Según el Censo de 2002 se entiende como población urbana la que reside en un "conjunto de viviendas concentradas en que residen más de 2000 habitantes, o entre 1001 y 2000 habitantes con $50 \%$ o más de su población económicamente activa dedicada a actividades secundarias y/o terciarias" (INE, 2003, p. 350 ).

3 Según el censo de 2002 cuenta con 6445 habitantes. 
núcleos de población como Vallenar, la capital provincial, y Copiapó, la regional. Vallenar en el valle transversal del río Huasco y Copiapó en el que lleva su mismo nombre. En el eje litoral se ubica Huasco y más al norte las ciudades de Caldera y Chañaral. Vallenar se caracteriza por su función minera y agraria, pero también por su función de servicios a nivel provincial. Huasco a 50 $\mathrm{km}$ de Vallenar es una ciudad con funciones agrarias, mineras y pesqueras, que recientemente ha adquirido una importante función portuaria y otra creciente de ciudad-balneario.

\section{El desarrollo industrial y la pervivencia de la agricultura tradicional: el binomio de la sostenibilidad territorial}

\subsection{La minería y la industria}

En el valle de Huasco la agricultura no es la principal actividad económica, como tampoco lo es en la región de Atacama, en donde se instauró un modelo extractivista a gran escala desde hace siglos. Este modelo de desarrollo generó importantes trasvases de población, aparición y desaparición consecutiva de aldeas y poblados mineros, creación de infraestructuras ferroviarias y portuarias, etc. A partir de mediados del siglo XX se ha orientado hacia la explotación de carbón, petcoke y la generación de energía hacia el resto del país, en una dinámica de desarrollo territorial desigual, como definiría el geógrafo inglés David Harvey (2012). Un modelo económico de libre mercado que se ha consolidado en esta y otras regiones de Chile a partir de la dictadura militar desde una concepción productivista y centralista del Estado (Salazar, 1999-2002). En el presente se manifiesta en un territorio que muestra una baja concentración de bienes y servicios, que ha visto modificados los modos de vida tradicionales y en el que las dinámicas sociales locales afrontan un conflicto espacial donde confluyen diferentes ideologías y paradigmas (Yáñez \& Molina, 2008). Los hitos industriales más importantes han sido los siguientes:

a) El siglo XIX hasta mediados del siglo XX

Tanto en Huasco como en Freirina, existieron importantes yacimientos de oro y cobre, hacia 1800. En Freirina los yacimientos de oro de Quebraditas, Labrar y Capote llegaron a identificarse como el "oro de Chile" en la sociedad de su época. En Carrizal Bajo llegó a instalarse una de las mineras de cobre más grandes de Chile y su ferrocarril y puerto de embarque fueron unos de los más importantes del país. La explotación del salitre (nitrato de Chile) sustituyó desde 1884 hasta la década de 1920 en las provincias de Tarapacá y Antofagasta a los agotados los filones de mineral de Atacama, en donde sus enclaves mineros vieron cerrar el ferrocarril y desaparecer buena parte de su población.

b) Desde 1952 hasta 1980

Millán (1999) denomina a esta etapa como la Mediana Minería del Hierro e industrialización del valle, puesto que fue esta minería la que ha dejó una huella más perdurable en la historia reciente 
del valle del Huasco: extensas heridas en el paisaje que dibujan los numerosos yacimientos del interior, corredores o vías de transporte, puertos mecanizados y plantas industriales en el litoral; es decir, todo un sistema articulado con la finalidad de manipular y exportar el mineral.

A principios de los 50, inician las actividades la minera Santa Fe y Santa Bárbara, la primera en Coquimbo y la segunda en Huasco. Santa Bárbara inició la explotación del yacimiento Huantemé en 1953, localizado al norte del valle del Huasco junto con los yacimientos Sositas, Chañar Quemado y Los Colorados. Gracias a la inversión extranjera, la minera mecanizó sus operaciones con la construcción del puerto Las Lozas que permitía cargar barcos de 50000 toneladas.

En los 60 se proyecta un muelle mecanizado con capacidad de 2500 toneladas por hora, llamado Puerto Mecanizado Guacolda, en la isla Guacolda, a 4 kilómetros de Huasco, uniendo la isla con el continente. Para albergar a los 2300 trabajadores empleados se iniciaron las primeras casas de la Quinta Valle de Vallenar y un poblado denominado CAP en Huasco.

La estatización de la mediana minería a comienzos de los años 70 supuso la desaparición de Santa Bárbara, que paso a formar parte de la Compañía Minera del Pacífico (CMP). La ampliación del puerto Guacolda (Guacolda II) para barcos de hasta 250000 toneladas de almacenaje y la construcción de la planta de pellets de hierro de CAP en 1978 supusieron un nuevo hito, no exento de problemas por los costos de generación eléctrica y la dificultad de extracción del mineral en El Algarrobo.

\section{c) Desde 1980 hasta el presente}

Hacia 1981 la recesión económica mundial se manifestó en la pérdida de la demanda de minerales y pellets, seguida de una bajada del precio del acero que afectó a la ahora privatizada CAP con la pérdida de ventas y la consecuente reducción de contratos de trabajo. A finales de la década se recuperaron las ventas y el personal empleado alcanzó a las 4000 personas y, a la par que se fue cerrando el yacimiento del Algarrobo, se iniciaba la explotación del yacimiento de los Colorados.

En la década de los 90 se instala en Huasco la termoeléctrica de Eléctrica Guacolda con la intención de dar estabilidad al suministro norte del Sistema Interconectado Central de Energía (SIC). La energía de la termoeléctrica se obtiene por la combustión de carbón y así continúa en el presente, por mor de la conectividad que otorga el puerto mecanizado en Isla Guacolda, que admite buques de carbón con gran calado, por la presencia de agua para enfriamiento y por la posibilidad de abastecer a las industrias de la región. Desde la primera unidad instalada hasta la quinta, aún en construcción, la central produce actualmente más de 4000 GWh, casi el $10 \%$ del SIC. 
Desde los inicios de año 2000 asistimos a la aparición de nuevos proyectos relacionados con la Mega Minería, propiciados por grandes transnacionales, los cuales han generado un gran rechazo social por las consecuencias medioambientales que podrían ocasionar.

El proyecto minero de Pascua Lama, de la minera canadiense Barrick Gold, se hizo con la intención de explotar las vetas de oro y plata de la parte alta del valle del Huasco y para ello preveía la remoción de los glaciares, lo que amenazaría el futuro hídrico del valle. El conflicto generado ha sido ampliamente documentado desde la geografía (Salinas, 2007), la ecología social (Urkidi, 2008; San Juan, 2011), e incluso desde el espectro de los derechos indígenas (Yáñez \& Molina, 2008). Finalmente el proyecto fue paralizado en el año 2012.

Otro proyecto que ha corrido igual suerte fue el de la minera Xstrata Cooper que aspiraba a la explotación de vetas de oro, cobre y plata en El Morro, un territorio Huascoaltino en el que los humedales y majadas conforman un ecosistema muy frágil.

En 2008 el holding Agrosuper lanzó el Proyecto Agroindustrial del Valle del Huasco, también paralizado, y que consistía en la construcción de un centro de producción porcino en Freirina, incluyendo la crianza y productos derivados, además de viviendas destinadas al personal encargado, que rondaría las 3000 personas. El Sistema de Evaluación Ambiental del Ministerio de Medio Ambiente constató riesgos para la salud por la posible contaminación del río Huasco por materiales percolados, efectos negativos sobre los recursos naturales, desplazamiento de comunidades y modificación de lugares calificados como patrimonio cultural. Tras una resolución de Calificación Ambiental favorable se inició el proyecto a la par que una resistencia ciudadana importante al mismo, que finalmente consiguió cerrar el complejo agroindustrial en 2013 (Vargas, 2014).

La eléctrica ENDESA ha visto paralizado también su proyecto de central termoeléctrica Punta Alcalde en 2012, que pretendía abastecer a las grandes mineras de cobre asentadas en el norte chileno. Los pescadores de Huasco y la Comisión Ambiental de Atacama se opusieron por la contaminación que se produciría en el Parque Nacional Llanos de Challe y la reserva nacional Pingüinos de Humboldt, especie endémica de Chile y Perú en peligro de extinción.

Es así como el valle del Huasco se encuentra comprometido desde su cabecera en las montañas andinas, su tramo medio y hasta la misma desembocadura por importantes mega proyectos industriales de inversión que explotan -o intentan hacerlo- no solo los recursos minerales sino los necesarios recursos hídricos, en clara competencia con las poblaciones allí asentadas y las actividades agrarias y pesqueras tradicionales. 


\subsection{La olivicultura tradicional del valle de Huasco}

El principal aprovechamiento agrario de Huasco, tanto por la extensión que ocupa como por el valor de la producción agraria final, es la olivicultura. Las actuales plantaciones tienen su origen en el siglo XVI a partir de las primeras estacas traídas por los españoles, procedentes del Perú, que alcanzaron el valle de Azapa y posteriormente el de Huasco. Desde entonces se han ido manteniendo a partir de retoños de los troncos de antiguas plantaciones, sobre todo las variedades de mesa (Tapia, 2003). Ya desde el siglo XVIII Huasco ocupó un lugar central como proveedor de los productos que alimentaron las faenas de los núcleos mineros de la región de Atacama y el Norte Grande de Chile (DIPLADE, 2010).

\section{Figura 4. Olivar centenario}

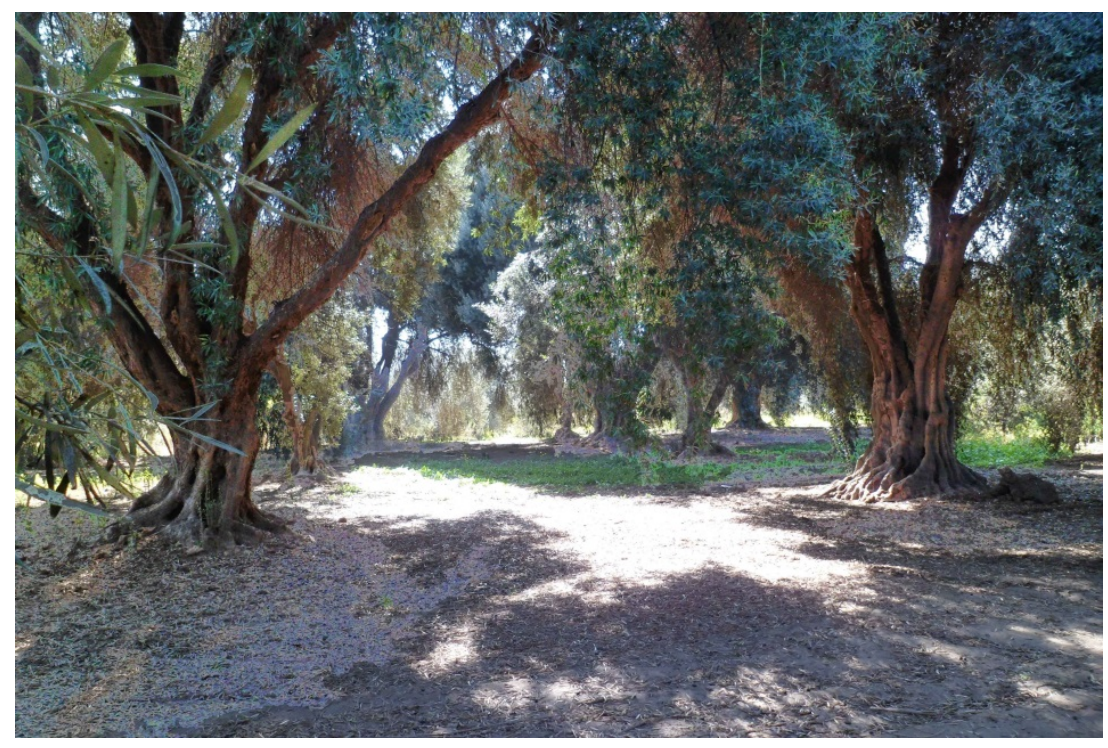

Fuente: fotografía de los autores (2015)

En la actualidad, el sector agrícola en Huasco se caracteriza por el desarrollo pequeñas y medianas explotaciones del olivar, que representan el 78,5\% del total regional. Esta agricultura coexiste con las plantaciones extensivas de uva de mesa, más abundantes en el valle medio y alto. Así los principales cultivos del valle en superficie son los forrajeros, seguidos por los de uva de mesa y olivos, pero también cuenta con una diversidad productiva que abarca desde los tradicionales tomates, ajíes, berenjenas, pepinos, zapallos, lechugas y pimentones, hasta cultivos más novedosos como la papa, palta, cítricos, arvejas, alcachofas y jojoba (DIPLADE, 2010).

En Huasco los huertos más antiguos cuentan aún con olivos centenarios (Figura 4), 4 que sin duda constituyen un caso de patrimonio agrario y rural único en Chile. También subsisten explotaciones

4 Recientes estudios hechos por la facultad de Agronomía de la Universidad de Concepción datan estos olivos con una antigüedad de unos 400 años, resultando estos posiblemente los más antiguos del país. 
que se establecieron con el criterio español que mantenía tres o cuatro estacas por hoyo de plantación en unos marcos muy grandes, que de media son de 10 × 10 m y que en algunos casos alcanza los $18 \times 18 \mathrm{~m}$. Incluso predomina una variedad procedente de las primeras estacas que trajeron los españoles: la Sevillano. Aunque también están presentes la Empeltre, la Gordal Sevillana y otras autóctonas como la Liguria, Manzanilla, Picuda de Huasco, Santa Caterina de Huasco, Ascolana de Huasco, entre otras.

Otra característica peculiar de las explotaciones es la superposición espacial de olivar y cultivos de huerta, aprovechando unos marcos tradicionales de plantación amplios. Tomate, melón, aji, sandías, vides, patatas, maíz dulce, etc., explotados de forma intensiva, salpican los olivares de Huasco. Estas especies hortícolas se producen de forma extratemprana o fuera de época, y de cultivarse con otras técnicas e infraestructuras como invernaderos podrían transformarse en interesantes alternativas productivas y económicas (INIA, 1997).

En términos generales los productores agrícolas del Huasco son variopintos. Hay un grupo tradicional de poca productividad, baja incorporación de tecnología, gestión y agregación de valor, básicamente ligado a la producción de forraje, aceitunas y uva pisquera. Le sigue un amplio y atomizado sector de agricultores con gran diversidad productiva y de medianos empresarios, de buen nivel técnico, orientados a la producción de paltas y cítricos. Finalmente es posible encontrar grandes productores de uva de mesa para la exportación (ARDP, 2007).

Figura 5. Explotación tradicional

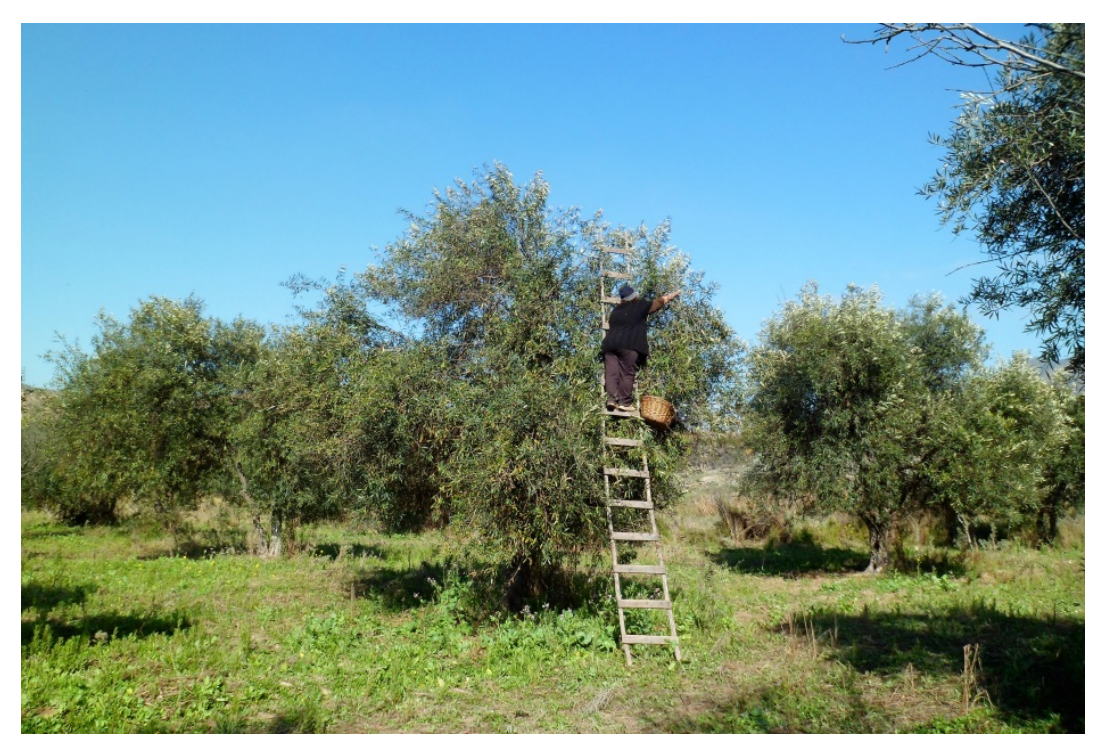

Fuente: fotografía de los autores (2015)

Los titulares de las explotaciones de olivar de Huasco detentan en su mayoría las propiedades de los terrenos, por lo que podemos afirmar que se está produciendo una explotación directa de la tierra (Figura 5), siendo el tamaño de estas pequeño y mediano, entre una y treinta y seis hectáreas, 
y contando un $60 \%$ de las explotaciones con una superficie inferior a 10 ha. La elevada edad media de los agricultores, los cuales superan en bastantes casos los setenta años (Sandoval, 2013), es otro de los problemas que afecta al futuro del olivar. La supervivencia actual del mismo no se explica si no es por el concurso de una mano de obra familiar que colabora en todas las tareas propias de estas explotaciones, y la solidaridad entre vecinos y los propios agricultores, que no ha sido suficiente, pues la falta de recursos y mano de obra llevó al abandono comunal de los tradicionales canales de drenaje con la consecuente progresiva salinización de los suelos. Los salarios son mucho más elevados en la industria que en la agricultura o en la pesca. Hecho que explica el progresivo abandono de las tierras de cultivo por los hijos de los agricultores y su temprana dedicación como asalariados a otras actividades que ofrecen seguridad y mayores ingresos. Así, por ejemplo, en la Comuna Huasco, los salarios del campo se encuentran por debajo de la media del país y la región, rondando los 248 dólares mensuales, cuando en la industria alcanzan los 556 dólares (Ministerio de Desarrollo Social, 2012).

La superficie de olivar en Huasco Bajo supera las 800 ha., siendo la principal variedad cultivada la sevillana. Esta variedad actualmente presenta períodos de añerismo muy marcados, lo cual afecta enormemente la producción de un año a otro, bajando de 80 a 1 kg por árbol en periodos de poca producción (INIA, 1997).

La mayor parte de la producción se orienta hacia la aceituna de mesa, aunque también en buena medida a la obtención de aceite, alternando pequeñas hazas de horticultura con zapallos de guarda, tomates, algo de maíz y habas. La aceituna de mesa es un producto agroindustrial natural que cada vez se valora mejor, su producción difiere de las elaboraciones tradicionales -como negras naturales o sajadas-, y comprende el segmento de exportación más grande -en formato granel- a Australia, Brasil, Arabia Saudita, incluso a Italia (Mora, 2013). A nivel empresarial se evidencia una fuerte concentración de las exportaciones de este tipo de aceituna, siendo la Agrosevilla Ltda. la que concentra más del $90 \%$ del mercado de exportación en valor. La comercialización en otros formatos, que no fuese a granel, podría ser una alternativa para ocupar esa creciente demanda y generaría una agroindustria importante, que agregaría valor a la cadena de los aprovechamientos agrarios, si bien el procesamiento de la producción requeriría incorporar estándares de calidad y comercialización del producto, lo que obligaría a la profesionalización de este rubro, partiendo desde la producción de huerto, y pasando por la industrialización y el conocimiento de los consumidores (Arrancibia, 2013). Esto obligaría a desarrollar una logística productiva y de comercialización, de manera que los productores de aceitunas del valle del Huasco podrían decidir adoptar este negocio de una manera moderna y sustentable.

La producción de aceites cuenta igualmente con condiciones favorables tanto por el cultivo de variedades de olivo cuyos aceites tienen un alto contenido de ácido oleico (Tapia, 2010), como por 
la existencia de una amplia tradición de almazaras familiares, que sin embargo no han evolucionado adecuadamente hacia una agricultura de mercado. ${ }^{5}$

\section{Principales retos del olivar}

La agricultura tradicional en el valle bajo de Huasco se encuentra comprometida no solo por la competencia que ofrecen las actividades industriales o por el envejecimiento de la población activa agraria, cuestiones ya tratadas en el apartado anterior, sino además por un grave problema relacionado con la salinidad de las tierras de cultivo, el empleo de unos sistemas de riego y fertilización deficientes, podas inadecuadas, escaso control del añerismo y una proliferación de diferentes plagas, a lo que hay que añadir una deficiente comercialización de la producción, o el deterioro de la condiciones ambientales. Todo ello ha confluido de manera que en el presente se ha producido una importante disminución de la producción y de la calidad de los frutos, con la consecuente pérdida de liderazgo en los mercados. Situaciones similares afrontan otros espacios linderos en espacios subdesérticos, como Tacna y Arequipa en Perú (Casapia, Navarro, Noriega \& Sáenz, 2005) o Catamarca, La Rioja, San Juan y Mendoza en Argentina (Gómez, Morales, Vita, Rousseaux \& Searles, 2010), si bien no acusan problemas tan graves como los que está provocando la salinización de suelos en Atacama.

\subsection{La restitución de los suelos}

Los suelos del valle bajo de Huasco se corresponden con una terraza aluvial de posición baja. Presentan un perfil de poco espesor, con un primer horizonte de color pardo, casi siempre franco arenoso y una estructura débil en bloques subangulares. El horizonte B es rojizo generalmente franco arcilloso. Ya en el horizonte $\mathrm{C}$ se detectan altas concentraciones de carbonato cálcico e incluso costras calcáreas que dificultan la profundización de las raíces y del agua (Díaz, 1957).

El olivo no es una planta exigente desde el punto de vista físico de los suelos, adaptándose a pronunciadas pendientes y a perfiles someros o pedregosos, si bien prefiere suelos de textura media a franca arenosa (Tapia, 2003). Aunque el olivo puede tolerar una salinidad alta, los suelos de Huasco son en extremo salinos (Figura 6), así uno de los principales problemas que afecta, no solo a la productividad del olivo, sino a su propia pervivencia, es la elevada salinidad y sodicidad que han ido acumulando a lo largo de los años (Céspedes, 1998). Hecho que se producido por el abandono de las tradicionales tareas de limpieza de los canales de drenaje, lo que ha ocasionado, a su vez, la progresiva acumulación de sales en los primeros horizontes de las tierras de cultivo y el consecuente daño a las matas de olivo.

5 Resulta perentorio la realización de una estadística actualizada -hoy en día inexistente- que recoja tanto las producciones totales anuales según las variedades de olivo, así como otra sobre el número y las características de las almazaras tradicionales -aún existentes-y las industriales. 
Figura 6. Perfil del suelo con altas concentraciones de sodio

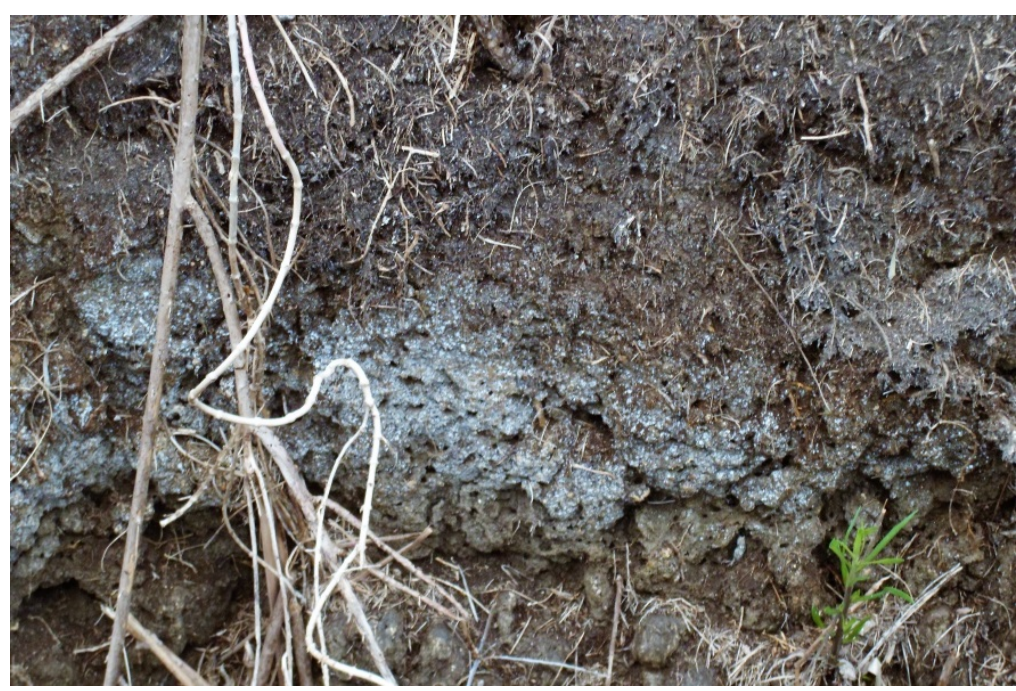

Fuente: fotografía de los autores (2015)

Este hecho, que es observable a simple vista en la superficie de los olivares, se ha estudiado en profundidad dentro del programa de Responsabilidad empresarial (PRS) Mi suelo es tu suelo que lleva a cabo el Departamento de Suelos y Recursos Naturales de la Universidad de Concepción. Así las muestras de suelo realizadas mediante el análisis tradicional del extracto de la pasta saturada han permitido evaluar la salinidad en 21 predios de Huasco Bajo (Tabla 1).

Tabla 1. Análisis químico de muestras de pasta saturada de suelos $(n=21)$

\begin{tabular}{|l|l|l|l|l|}
\hline Identificación & Unidad & Mínimo & Promedio & Máximo \\
\hline $\mathrm{Ce}$ & $\mathrm{dS} \mathrm{m}^{-1}$ & 3,05 & 17,70 & 113,00 \\
\hline $\mathrm{Na}$ & $\mathrm{mmol}^{+} \mathrm{L}^{-1}$ & 5,83 & 43.09 & 178,35 \\
\hline $\mathrm{Ca}$ & $\mathrm{mmol}^{+} \mathrm{L}^{-1}$ & 3,90 & 31,57 & 182,40 \\
\hline $\mathrm{Mg}$ & $\mathrm{mmol}^{+} \mathrm{L}^{-1}$ & 1,94 & 35,29 & 265,68 \\
\hline $\mathrm{K}$ & $\mathrm{mmol}^{+} \mathrm{L}^{-1}$ & 0,36 & 3,04 & 16,78 \\
\hline $\mathrm{RAS}$ & & 2,34 & 8,05 & 28,16 \\
\hline $\mathrm{PSI}$ & & 2,15 & 8,95 & 28,71 \\
\hline
\end{tabular}

Fuente: Sandoval (2013)

Los valores de Ce no son inferiores a 3,05 dS m-1 (Decisiemen por metro), con picos superiores a 100 y un promedio de 17,70 dS m-1 que ya es considerado como extremadamente salino. ${ }^{6}$ Son las altas concentraciones de sodio ( $\mathrm{Na}$ ) las que explican la elevada salinidad con una concentración molar entre los 5,83 y los 178,35 mmol+L-1. Los efectos del sodio son tóxicos para las plantas y provocan el quemado y la muerte de tejidos comenzando por la periferia de las hojas y progresando hasta el centro. También se detectan altos niveles en los cloruros como el cálcico, el

6 El límite entre suelos salinos y no salinos el valor de CE es de 4,0 dS m-1 en el extracto de la pasta saturada. 
magnésico o el potásico que afectan negativamente al crecimiento y desarrollo de las plantas. La evaluación de la relación del sodio con la actividad del calcio y el magnesio soluble permiten calcular la Razón de Absorción de Sodio (RAS). Cuando los valores son inferiores o iguales a 5 indican la inexistencia de dificultades para la infiltración del agua en los suelos y cuando los valores son superiores aumentan los problemas de infiltración, haciendo menos eficiente el riego y produciendo la acumulación de sales en la superficie. Pues bien, el 48 \% de las muestras presentaron valores menores a 5 y el resto lo hizo por encima, además el promedio de las muestras tomadas es superior a 8, así todos los datos apuntan a la escasa capacidad de filtración de los suelos, la cual se manifiesta visualmente en la presencia de abundantes costras salinas en superficie. En definitiva, teniendo en cuenta los análisis de muestras y ponderando la razón de absorción de sodio (RAS) y el porcentaje de intercambio de sodio (PSI), los suelos de Huasco Bajo se pueden clasificar como Salinos y/o Salinos-sódicos (Sandoval, 2012, p. 12). Diagnostico este que resulta ser de gran importancia para poder hacer efectivas diferentes propuestas en el manejo y restitución de los suelos de la comuna.

Para realizar un estudio completo de los suelos y conocer las potencialidades de esto se ha llevado a cabo un análisis físico de 21 muestras utilizando los parámetros tradicionales (Tabla 2).

Tabla 2. Análisis físico de muestras de suelos de Huasco bajo $(n=21)$

\begin{tabular}{|l|l|r|r|r|}
\hline Identificación & Unidad & Mínimo & Promedio & Máximo \\
\hline $\mathrm{Da}$ & $\mathrm{g} \mathrm{cm}^{-3}$ & 0,8 & 1,2 & 1,31 \\
\hline $\mathrm{Ha}$ & $\% \mathrm{hbss}$ & 6,01 & 11 & 13,9 \\
\hline
\end{tabular}

Fuente: Sandoval (2013)

La densidad aparente (Da) promedia 1,2 g cm-3, valor que resulta adecuado pues indica que no existen problemas de compactación en los primeros horizontes del suelo hasta una profundidad de $30 \mathrm{~cm}$ en la que se ha realizado el muestreo. La densidad aparente se explica por la clase de textura dominante de los suelos. Franco, franco arenoso y franco limoso son las que predominan, dado que las arcillas no sobrepasan el $25 \%$ en ninguna de las muestras tomadas. Este análisis permite también proyectar el ajuste de los fertilizantes adecuados que se deben aplicar al suelo. La humedad aprovechable ( $\mathrm{Ha}$ ) evalúa la capacidad de almacenar agua disponible para los cultivos. El promedio es el $11 \%$ de humedad base suelo seco (hbss), que puede considerarse como un valor intermedio en este tipo de suelos. Conocidos estos valores se evidencia la capacidad de estanque para almacenar agua del suelo y así se puede planificar el riego adecuado, que no obstante pueden verse perjudicada y producirse una pérdida de materia orgánica de persistir los malos manejos con el agua de riego.

Los análisis químicos (Tabla 3) ratifican los análisis de pasta saturada y permiten identificar nuevos problemas a la vez que muestran la aptitud agronómica de los suelos. 
Tabla 3. Análisis químico de las muestras de suelo de huasco bajo $(n=10)$

\begin{tabular}{|l|l|r|r|r|}
\hline \multicolumn{1}{|c|}{ Identificación } & \multicolumn{1}{c|}{ Unidad } & Mínimo & Promedio & \multicolumn{1}{c|}{ Máximo } \\
\hline Mo & \% & 1,75 & 2,73 & 4 \\
\hline $\mathrm{Nd}$ & Mg Kg-1 & 7 & 35,82 & 168,2 \\
\hline Fosforo Olsen & Mg Kg-1 & 1,5 & 27,45 & 80,5 \\
\hline K intercambiable & Cmol Kg-1 & 0,36 & 0,77 & 2,25 \\
\hline Ca intercambiable & Cmol Kg-1 & 15,45 & 45,78 & 121,9 \\
\hline Mg intercambiable & Cmol Kg-1 & 1,97 & 5,78 & 14,14 \\
\hline $\mathrm{Na}$ intercambiable & Cmol Kg-1 & 0,74 & 8,33 & 28,06 \\
\hline $\mathrm{pH}$ & & 7,47 & 7,98 & 8,31 \\
\hline
\end{tabular}

Fuente: Sandoval (2013)

La materia orgánica $(\mathrm{MO})$ es muy escasa pues varía entre 1,75 y $4 \%$. El Nitrógeno disponible arroja valores de medio a bajos, aunque algunas muestras dan concentraciones muy altas debidas posiblemente a una incorrecta aplicación de fertilizantes nitrogenados. Los niveles de fósforo son adecuados, igual que los de potasio, mientras que calcio, magnesio y sodio son altos. El ph es alto también como corresponde a suelos con un alto contenido de sales.

Las aguas de riego empleadas tampoco resultan ser las más adecuadas para los cultivos. Las muestras realizadas en diez predios concluyen que se encuentran dentro del rango de aguas salinas. En la Tabla 4 se muestran los analitos que verifican la salinidad.

Tabla 4. Análisis químico de las muestras de agua de Huasco bajo $(n=10)$

\begin{tabular}{|l|l|r|r|r|}
\hline \multicolumn{1}{|c|}{ Identificación } & Unidad & Mínimo & Promedio & Máximo \\
\hline $\mathrm{Ce}$ & $\mathrm{dS} \mathrm{m}$ & 3,26 & 3,50 & 10,89 \\
\hline $\mathrm{Na}^{+}$ & $\mathrm{mg} \mathrm{L}^{-1}$ & 420 & 453 & 1640 \\
\hline $\mathrm{CL}^{-}$ & $\mathrm{mg} \mathrm{L}^{-1}$ & 383,96 & 539,80 & 1665,58 \\
\hline $\mathrm{HCO}_{3}{ }^{-}$ & $\mathrm{Meq} \mathrm{L}^{-1}$ & 4,70 & 5,31 & 9,10 \\
\hline $\mathrm{B}$ & $\mathrm{mg} \mathrm{L}^{-1}$ & 0,67 & 1,21 & 3,87 \\
\hline $\mathrm{pH}$ & & 8,05 & 8,22 & 8,58 \\
\hline
\end{tabular}

Fuente: Sandoval (2013)

La conductividad eléctrica $(\mathrm{Ce})$ es uno de los indicadores más significativos de la salinidad de las aguas de Huasco que alcanzan valores promedio de 3,5 dS m-1 y alguna muestra que supera los 10 dS m-1. Las concentraciones de $\mathrm{Na}+$ alcanzan valores promedio altos (453 mg L-1) y alguno incluso tóxico para las plantas $(1640 \mathrm{mg}$ L-1). Estos resultados, elevados también en los cloruros (CL-) y los bicarbonatos (HCO3-), restringen el uso del regadío solo a cultivos muy tolerantes como es el olivo, que se ve afectado y en algunos casos sobrevive en suelos estructuralmente desorganizados, puesto que el $\mathrm{Na}+$ desplaza el calcio y el magnesio del complejo arcillo-húmico, provocando la dispersión de las partículas del suelo. La presencia de boro es igualmente elevada, con un promedio de 1,21 mg L-1. Aunque es un elemento imprescindible para los cultivos en bajas concentraciones, cuando supera los $1 \mathrm{mg} \mathrm{L-1} \mathrm{se} \mathrm{vuelve} \mathrm{tóxico} \mathrm{(Bingham,} \mathrm{Strong,} \mathrm{Rhoads} \mathrm{\&} \mathrm{Keren,}$ 
1985). Dándose el caso que solo una muestra ofrecía valores inferiores. El pH del agua con unos valores medios superiores a 8 indica una alcalinidad moderada que puede ocasionar deficiencia de hierro en los frutos y aceites derivados. No obstante el uso adecuado de determinados fertilizantes y el empleo de un riego tecnificado, que permita acidificar el agua minimizan la alcalinidad. En definitiva, la elevada salinidad que apreciamos en todos los analitos se debe a una concatenación de causas naturales y humanas. Por un lado, la propia mineralogía de la cuenca aporta concentraciones elevadas de sodio a las aguas de escorrentía y a los cursos fluviales, además la elevada evapotranspiración, unida a los problemas de un inadecuado drenaje, ocasiona la formación de costras salinas en la superficie de los suelos. Por otro lado, las actividades humanas que soporta la cuenca como la minería, la ganadería o la propia agricultura supone el incremento de los analitos descritos - particularmente los cloruros, porcentaje de sodio y CE- hasta valores que sobrepasan la norma oficial chilena de Calidad de Aguas de Riego (Instituto Nacional de Normalización, 1999) y la guía CONAMA (2004) para el establecimiento de las normas secundarias de calidad ambiental para las aguas continentales superficiales y submarinas.

En otros tiempos las limitaciones que imponían los suelos y las aguas de riego eran solventadas en mayor o menor medida por técnicas tradicionales de laboreo y el mantenimiento a azada de canales de drenaje. Actualmente la situación de las explotaciones ha llegado a ser insostenible por la existencia de mano de obra insuficiente, la escasa tecnificación de unas explotaciones que producen un escaso rendimiento y el abandono de los ancestrales canales de drenaje. Las soluciones aplicadas dentro del programa Mi suelo es tu suelo se han centrado fundamentalmente en la limpieza con maquinaria pesada de los canales de drenaje, por un lado. Por otra parte se ha iniciado la restitución de los suelos con un fertilizante del tipo enmienda, compuesto por sulfato de calcio hidratado $\left(\mathrm{CaSO}_{4} \times 2 \mathrm{H}_{2} \mathrm{O}\right)$. Este producto se encuentra paradójicamente en abundancia en Huasco y proviene del proceso de abatimiento de las emisiones de la Central Termoeléctrica Guacolda. Los resultados de estas actuaciones buscan una reacción en cadena hasta que las plantas recuperen su vigor, tamaño, alcance radicular, diámetro de los bordes, floración, carga frutal y finalmente su rendimiento.

\subsection{La explotación del olivar}

La explotación adecuada del olivar radica en la integración de tres aspectos complementarios: el riego, la fertilización y la poda.

a) Riego

El olivo es una planta adaptada a la sequía estacional, propia de climas mediterráneos, e incluso resistente al clima desértico, como es el de Huasco. Si bien, es cierto que para cubrir los requerimientos hídricos mínimos del olivo, que no alcanzan a cubrir las escasas precipitaciones invernales, es preciso el aporte de agua del riego. La elevada evapotranspiración potencial anual 
reduce la eficiencia de las escasas lluvias y eleva los requerimientos de riego a unos 6000-8000 $\mathrm{m}^{3}$ /ha/año (CIREN-CNR, 1997). Así, dada la escasez e irregularidad de las precipitaciones en la región y la elevada evapotranspiración, los olivares dependen del riego que se extrae del río Huasco y de los pozos localizados en el manto freático de dicho valle. Dichos aportes permiten obtener una buena producción y reducir el añerismo.

Tradicionalmente se llevan a cabo sistemas de riego gravitacional de escasa eficacia como el de inundación, que se aplica directamente a la superficie de la explotación, conduciendo el agua por canales estrechos (riego por surcos), por láminas de agua limitadas por pretiles o camellones (riego por bordes), con pequeños estanques en cada árbol (riego por tazas), o sin ningún tipo de limitación (riego por tendido). Estos sistemas presentan una escasa eficiencia pues se pierde una parte importante del agua, con la circunstancia añadida de que nos encontramos en una región en donde resulta ser un recurso escaso y por el que pugnan también las poblaciones y las industrias instaladas en el valle. Además del agua que se pierde por la evapotranspiración o por escurrimiento hacia los drenes, se desaprovecha la que se infiltra allí donde no hay raíces, o en los horizontes más profundos del suelo. Incluso los que lo hacen por goteo o microaspersión carecen de controles de eficiencia de riego y mantenimiento de los equipos. La frecuencia de riego tampoco ha sido la más adecuada pudiendo llegar a 20 días entre riegos, lo que agrava bastante el añerismo de la especie.

La optimización del riego del olivar en Huasco pasa necesariamente por la aplicación de parámetros técnicos y sistemas modernos como el riego por goteo o tecnificado, lo que requeriría de unas cuantiosas inversiones para los olivareros de Huasco, además de la adquisición de unos conocimientos técnicos adecuados. Pero también es preciso renovar las infraestructuras de riego a escala comunal e intrapedial, mejorando, por ejemplo, el almacenaje en tanques comunitarios o estableciendo turnos de riego (Martinez, 2002; INIA, 1997).

\section{b) La fertilización}

El olivo no es una planta demasiado exigente en cuanto a nutrientes, es un árbol que tolera incluso suelos marginales, esqueléticos o con grandes pendientes. Ahora bien, al igual que otras especies productivas, requiere de una concentración óptima de macronutrientes para producir frutos. Tradicionalmente se ha fertilizado con abonos naturales como los guanos o con estiércol de caprino, que mejoraba las condiciones de salinidad, pero que era insuficiente a la hora de aportar los nutrientes requeridos que precisaban las grandes producciones de décadas anteriores.

Los suelos salinos y/o salinos-sódicos del valle de Huasco, que en buena parte aparecen lavados y con escasa materia orgánica en los horizontes más superficiales por el sistema de riego gravitacional empleado, requieren de aportes o fertilizantes, los cuales se podrían incorporar adecuadamente si se utilizan sistemas de riego tecnificado (INIA, 1997). La demanda de nutrientes 
minerales del olivo depende de los marcos de plantación, edad de las matas y sobretodo de la biomasa vegetal que forman anualmente. El nitrógeno es el componente que más demanda el olivar y se consigue aumentar con nitrato de amonio. El potasio es también necesario pero ya existe de forma natural en los suelos de Huasco. Los aportes de fósforo, magnesio y calcio resultan también necesarios en todas las explotaciones.

\section{c) La poda}

El manejo tradicional sin poda ha configurado unos olivares de una altura extraordinaria, que en la distancia asemejan bosquetes entre las explotaciones modernas de olivar. La falta de podas periódicas y adecuadas no favorece la floración y causa el autosombreamiento del follaje en la misma mata y entre unas y otras. El resultado es una pérdida considerable de la superficie productiva (Ibacache, 1988).

Con una poda apropiada, que abra el centro del árbol, se logra una mayor exposición al sol y así se estimula el crecimiento de nuevos brotes frutales. Al limitarse también la altura del olivo, las labores sucesivas y la recogida del fruto se facilitan. Es preciso que los agricultores, mediante una formación actualizada, conozcan y apliquen las prácticas de poda, equilibrando el crecimiento y la fructificación de sus olivares. Ellos son los que conocen la edad del huerto, el tamaño de los árboles, la densidad de plantación, la cosecha del año anterior y el destino de su producción. Elementos todos ellos necesarios para determinar el tipo de poda, bien de formación, de producción, o por el contrario de rejuvenecimiento o renovación (Tapia, 2003).

d) El control del añerismo y de las plagas y enfermedades del olivo

El añerismo, muy acentuado en este valle, produce una fluctuación productiva muy intensa, de manera que algunos años apenas si hay producción (Cooper, 2001). Las características climáticas no parecen ser la causa más decisiva del añerismo, más bien se produce por una fertilización escasa o inadecuada, o una poda nula o muy intensa, además de por el repilo, que produce la pérdida de follaje sobre todo en la variedad negra natural y en menor medida en la variedad sevillano (Tapia y Arrancibia, 2006). No es posible evitar el añerismo por completo, aunque sí reducir sus efectos mediante prácticas de poda y fertilización realizadas con criterios técnicos. Cuando se prevé una baja producción, la poda debe ser ligera y la fertilización escasa. Así se evita un exceso de crecimiento, que competiría con el desarrollo de los frutos ya escasos de por sí. (Ibacache, 1987).

De más del centenar de plagas que afectan al olivo, son seis las que se han detectado en el valle de Huasco (Ibacache, 1987). Las más graves son: el llamado Emplomado producido por un hongo que afecta al fruto, la vericosis que produce incluso la muerte del árbol en los injertos de Sevillano y la verticilosis que deseca parcialmente el árbol. La Cochinilla se encuentra entre las plagas entomológicas más graves. En los años 60 diezmó los olivares de Huasco, sin embargo, en la 
actualidad existe un control biológico que hace innecesario el empleo de pesticidas. El tratamiento para el control de estas enfermedades se realiza tanto con fungicidas como de forma natural mediante el control biológico que ejercen algunas avispas del género Metaphycus y una cochinilla denominada Cryptolaemus monstruozieri. Pero es igualmente importante una poda que permita una copa bien ventilada que reduce las condiciones de propagación de dichos hongos (Montealegre, 2009).

\section{Hacia la construcción de un territorio ambiental, social y económicamente sostenible}

La olivicultura del valle bajo de Huasco afronta importantes retos que comprometen su presente más inmediato como acabamos de analizar en el apartado anterior, empero existen otros que igualmente son importantes y que comprometen seriamente su futuro. Una cuestión pendiente es la mejora genética de las diferentes variedades de olivo que permitiría mejores rendimientos con variedades más productivas y adaptadas a las características fisiográficas del desierto de Atacama (Mora, 2013).

La región de Atacama, y de forma particular los valles de esta Región (Huasco, Copiapó), presentan un potencial para desarrollar la agricultura ecológica, y no solo del olivar, sino también de otros aprovechamientos como el frutícola, hortícola y vitícola (ODEPA, 2011). La olivicultura de Huasco tendría una importante oportunidad en los mercados ecológicos si dedicase una parte de su producción de olivas y aceite a ellos. Para lo cual requeriría de la constitución de grupos de agricultores ecológicos a los que se facilitase una adecuada capacitación con los oportunos instrumentos de fomento.

La capacitación agraria y educación es otra asignatura pendiente. Es necesario fortalecer la formación de recursos humanos con jóvenes expertos en agricultura de zonas áridas, mediante la incorporación de esta especialidad en los institutos y universidades regionales. Como también es preciso fortalecer la capacitación profesional de los agricultores ya mayores mediante cursos específicos adaptados a sus necesidades.

\subsection{Crisis ambiental y espacios protegidos}

El valle de Huasco cuenta con un ecosistema extraordinariamente rico a la vez que extremadamente frágil en razón de sus componentes naturales. Prueba de su biodiversidad es la existencia de unas formaciones vegetales xerofitas muy frágiles en función de un clima, unos suelos y una geomorfología características (Gajardo, 2005). De igual manera, la fauna adaptada a estos ecosistemas presenta un elevado grado de endemismo, con numerosas especies en riesgo de extinción (Benoit, 2002). En aras de la conservación de estos ecosistemas únicos, el Estado chileno ha creado mecanismos de conservación dependientes de diferentes ministerios y servicios como es 
la Comisión Nacional del Medio Ambiente, la Corporación Nacional Forestal y el Consejo Nacional de Monumentos. Destacan entre los Sitios Prioritarios para la Conservación (CONAMA, 2007): E Desierto Florido, las Lagunas HuascoAltinas y Alrededores, y el Estuario Río Huasco y Laguna Carrizal, que es el lugar de mayor presencia de avifauna en la región. Además en la proximidades de Huasco se encuentran importantes parques nacionales como: Parque Nacional Pan de Azúcar, el Parque Nacional Nevado Tres Cruces, el Parque Nacional Llanos de Challe y la Reserva Nacional Pingüino de Humboldt.

La competencia por un recurso tan escaso como es el agua se ha tornado en el epicentro de muchos de los conflictos territoriales. ${ }^{7}$ A este respecto Torres (2009) recomienda adoptar las directrices de la Directiva Marco del Agua (DMA) dictada por el Parlamento Europeo el año 2000, de manera que se llegue a la integración de todos los usos, valores y funciones del agua en un marco de política común: "el agua para el medioambiente, agua para la salud y el consumo humano, agua para los sectores económicos, transporte, turismo, el agua como un bien social" (Torres, 2009, p. 697)

Es en este frágil ecosistema se desarrollan diversas actividades productivas, siendo la actividad minera la principal. Fue uno de ellos, el megaproyecto Pascua Lama, el que abrió la discusión respecto a la sustentabilidad hídrica del Valle. Desde entonces, diversos colectivos sociales de olivicultores, pescadores y grupos ambientales han interpuesto recursos de protección en defensa de sus actividades y del medio ambiente contra la CMP, Agrosuper y el resto de compañías mineras y eléctricas (Durán, 1989; Elgueta, 2012).

Sin embargo, también se da el caso, de que las industrias asentadas en el Valle asuman proyectos de responsabilidad social, no sin cierta controversia, encaminados a aportar soluciones a la agricultura y a las comunidades en las que se asientan.

7 En Chile, según el Código de Aguas, los derechos de aguas se obtienen a "perpetuidad", pudiendo los titulares poner a la venta estos derechos. Es así como se ha ido formando lo que se llama "el mercado de aguas chileno". 


\section{Figura 7. Recuperación de los antiguos canales de drenaje}

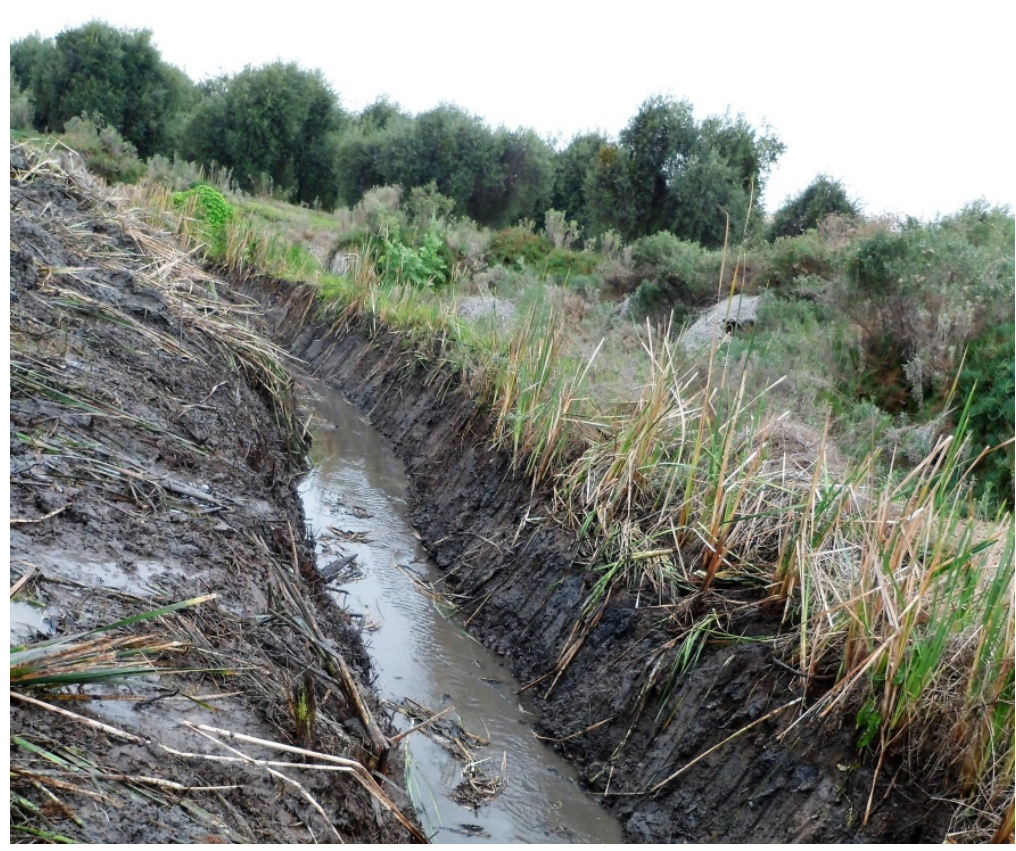

Fuente: fotografía de los autores (2015)

\subsection{Proyectos de responsabilidad estatal y empresarial}

Se vienen realizando desde hace unas décadas acciones a corto y medio plazo de apoyo social en beneficio de los agricultores del valle de Huasco. Entre otros proyectos de responsabilidad estatal y empresarial que se han llevado a cabo o están en curso destacamos:

- En 1993 se firmó un convenio entre la Universidad de Chile y la Compañía Minera del Pacifico S. A. destinado a poner en marcha el proyecto de investigación titulado "Mejoramiento de la Productividad del Olivo en el Valle del Huasco" que incluía actuaciones de productividad en Los Olivos de Bellavista (Castelleto, 2001).

- Entre 1997 y 2000, en el mismo predio de Bellavista, el anterior proyecto se completó con otro titulado "Añerismo del olivo en el valle del Huasco: factores, problemas asociados y medios de control".

- En 1996 el Gobierno Regional de Atacama financió un primer proyecto de cinco años de investigación-desarrollo para incorporar nuevas tecnologías y aportar soluciones a los problemas más perentorios del olivar Huascaltino. El Centro Regional de Investigación Intihuasi del INIA lo llevó a cabo.

- En 2013 se inicia otro proyecto mediante un convenio entre la Universidad de Concepción y Guacolda Energía titulado: "Mi suelo es tu suelo", que ha establecido un modelo de acompañamiento a los agricultores con propuestas de mejora, compartidas y acordadas. Parte 
de acciones piloto encaminadas a mejorar los actuales problemas productivos en los olivares y sus actuaciones se centran en:

- El mejoramiento de la red de drenaje intrapedial (Figura 7), mediante el empleo de maquinaria agrícola pesada -de la que carecen los agricultores-, con el fin de mitigar los problemas de salinidad y sodicidad que presentan los suelos, y que de no llevarse a cabo con prontitud podría situar al olivar de Huasco en una situación de pérdida irreversible. Los primeros efectos ya se han hecho notar, pues estos drenes han disminuido el alza capilar que eleva las sales del suelo hacia la superficie del mismo y se va efectuando el correcto lavado del sodio y otros compuestos.

- El manejo tecnológico del riego, tanto gravitacional como tecnificado para mejorar su eficiencia de uso y otros manejos específicos de los suelos.

o La restitución de suelos con un fertilizante del tipo enmienda, compuesto por sulfato de calcio hidratado $\left(\mathrm{CaSO}_{4} \times 2 \mathrm{H}_{2} \mathrm{O}\right)$ procedente de los abatimientos de la central Guacolda y que se incorporará a los suelos de diferentes predios y de forma anual. El cual, una vez hecho el lavado de sales, debe permitir aumentar la presencia de otros elementos benéficos para el cultivo como el calcio, el azufre y el magnesio.

\subsection{La resistencia social y la creación de lazos afectivos con el territorio}

La asociatividad agrícola y ambiental de Huasco hunde sus raíces en un proceso cuyos antecedentes se vinculan directamente con la llegada de proyectos de gran impacto para la actividad del Valle, que han ocasionado conflictos étnicos (Gajardo, 2014) y territoriales de gran impacto (Urkidi, 2008; Vargas, 2014). A partir de diferentes modos de entender el territorio se han formado nuevos movimientos ciudadanos como la agrupación Consejo de Defensa del Valle del Huasco, el Movimiento Socio Ambiental Valle del Huasco, o la Asociación Gremial Agrícola de la Provincia del Huasco, entre otros. Estos movimientos ciudadanos, a la par que defienden su territorialidad, reivindican un conjunto de prácticas sociales, relaciones e identidades que se configuran en torno a las actividades agrícolas (DIPLADE, 2010). La crisis agraria, la emigración y la competencia de otras actividades han producido la falta de sentido de pertenencia o la pérdida progresiva de elementos culturales, de los ritos y ceremonias de las sociedades agrarias del Valle, en la que la vida cotidiana se organizaba según los ciclos productivos y sus vulnerabilidades climáticas.

Es preciso recuperar los lazos afectivos con el territorio, la imagen de un Huasco de tradiciones olivícolas acrisolado por generaciones de agricultores, pues precisamente el territorio y los espacios vividos, son espacios cargados de símbolos y de identidad, arraigo y sentido de pertenencia a la comunidad local. La identidad de lugar se fundamenta en el encuentro entre el ambiente, el individuo y el grupo. Implica un sentido de pertenencia, enraizamiento, normas y valores sobre un 
espacio común y personal (Muntañola, 1996). Esta identidad se verifica cuando todos los que se reconocen en lugares comunes comparten algo en común, un espacio que alberga referencias históricas, espaciales, culturales y sociales. Es preciso recobrar el sentido de una comuna de Huasco que cobije a los individuos, que sea lugar de reconocimiento, de memoria histórica, lugar de adquisición de saberes, de compartir y decidir.

Y, si bien es necesaria una nueva visión del desarrollo que aleje Atacama de la lógica neoliberal que se caracteriza por una desigual acumulación de riqueza, respecto a personas como a territorios, generando dependencias y precariedades,$-{ }^{8}$ también es cierto que Atacama es una región minera desde la fundación de país en 1540. A las generaciones presentes toca por tanto reconocer la identidad de un territorio compuesto por un rico patrimonio natural y formas de vida diferentes, abordando un proyecto de desarrollo comunal consensuado. Es decir, un proyecto que moldee la identidad cultural con el desarrollo territorial como fundamento de cohesión, participación y reflexión (DIPLADE, 2010). El fortalecimiento de la identidad permite, a su vez, insertar la participación social dentro de la lógica del desarrollo económico y la promoción de la competitividad. Es aquí cuando cobra sentido el pensamiento de lograr una olivicultura competitiva, una vez garantizada la supervivencia de las explotaciones, y para ello, los agricultores de Huasco deben utilizar la diferencia como valor añadido de la calidad y la comercialización de sus productos. La incorporación de valor agregado a la aceituna debe ser un proceso continuo, en donde se vayan diversificando los productos junto a la apertura de mercados de mayor exigencia, hacia sectores que demanden mayor valor agregado (Mora, 2013).

\subsection{Nuevas políticas urbanas y territoriales}

En la búsqueda del equilibrio económico y territorial se requiere también de acertadas políticas de planificación urbana que establezcan una zonificación coherente de los espacios comunales y que concilien los diversos usos del suelo, el de las diversas actividades productivas con el de las zonas residenciales y lo espacios de uso público, respetando la escala humana y el patrimonio arquitectónico e industrial. Una cuestión importante por resolver es el tránsito de ferrocarriles cargados de mineral por el interior de Huasco y otra, no menos perentoria, la de integrar la localidad con Huasco puerto. El borde costero y el estuario del río Huasco quedan igualmente escasamente integrados, cuando podrían suponer una oportunidad de integración regional y turística conectando dicho espacio protegido con la ciudad y la Ruta de la Costa (MINVU, 2009)

Los paisajes de Huasco constituyen un importante recurso pues reflejan los procesos que tienen lugar en el territorio, resultado de la interacción entre lo natural y lo humano. Los kilómetros de costa que presenta, los relieves montañosos andinos de telón de fondo en la cabecera de un valle

8 Conocida dentro de la ecología políitca como la teoría de los desarrollos territoriales desiguales (Harvey, 2007). 
agrícola fértil y verde, encajado en una diversidad de ambientes áridos, a modo de río Nilo, todo ello constituye un escenario espectacular y único. Además, los espacios naturales protegidos, el poblamiento de la región y una cultura ancestral, ofrecen a los potenciales turistas un destino inigualable. Los vestigios de la cultura Diaguita, incluso los restos de arqueología industrial de la región, conforman un recurso turístico importante. Por consiguiente, la variedad de recursos turísticos permitiría también la diversidad de diferentes sectores turísticos como el ecoturismo, el turismo cultural rural o el de sol y playa. El turismo rural, apenas explotado, pensamos que puede constituir una de las principales vocaciones turísticas de Huasco a partir de unos paisajes de la olivicultura que conservan huertos de olivos centenarios o almazaras familiares tradicionales, aún en funcionamiento. Lo que significa que, de hacer un uso de estos recursos, estos necesariamente se deben proteger para asegurar su continuidad, la de las familias de agricultores y de las actividades sostenibles que realizan. Por otro lado, la sustentabilidad de la actividad turística en este valle no es fácil de mantener, dada la escasa capacidad de carga que presentan estos ecosistemas naturales tan frágiles, unos paisajes agrícolas tradicionales o unas comunidades rurales con escasos servicios o deficientes estructuras viarias.

\section{Consideraciones finales}

La olivicultura en Huasco Bajo continúa siendo la principal actividad agrícola de la comuna y la que mayor extensión ocupa. Entre los factores de tipo físico que condicionan la actividad agraria es destacable la existencia unas temperaturas no letales para las plantas y ausencia de heladas, si bien existe un importante déficit hídrico que se resuelve mediante el riego que proporciona el río Huasco. Las aguas de riego superficiales, aunque vienen a paliar el déficit hídrico, contienen altos contenidos de sales y en la práctica han aumentado la salinidad de unos suelos francoarenosos escasamente desarrollados. Tampoco presentan una eficiencia adecuada los sistemas de riego y fertilización, y aunque se han ido incorporando los conocimientos de la nueva olivicultura en los huertos más modernos, la envejecida población agraria que los atiende no cuenta con los recursos económicos, de formación y un relevo generacional que continúe con las explotaciones de sus ancestros.

El concurso de la minería y de los grandes proyectos supone un gran reto a la agricultura tradicional del Valle, tanto por la competencia por el agua como por los riesgos ambientales que genera, lo que para algunos significa la pérdida del valor de la tierra y el fin de la tradición agrícola del valle. Pero, tanto la tradición agrícola como la minera forman parte del paisaje del valle de Huasco en los últimos siglos y deben de convivir en aras de un desarrollo sostenible.

Es necesario continuar y ampliar los programas de apoyo institucional y empresarial, así como unas políticas de investigación y transferencia tecnológica que sustenten a esta agricultura en peligro. Pero también es necesario promover políticas de apoyo a las pequeñas y medianas empresas 
agrícolas, fortalecer los canales de distribución de los productos locales y su proyección exterior, de manera que se produzca una secuencia y diversificación de actividades productivas. La diversificación económica es una exigencia decisiva en una comuna que hasta ahora obtiene sus mayores ingresos de la actividad minera y la producción de energía, e incidiría en un mayor equilibrio territorial, facilitando la construcción de nuevas centralidades con mayor accesibilidad y mejor distribución de los servicios y equipamientos públicos.

Tampoco se puede soslayar la necesidad de una capacitación profesional en institutos y escuelas que incentive una mayor valoración del patrimonio y de la cultura rural del Valle a la vez que forme recursos humanos especialistas en olivicultura y en agricultura de zonas áridas.

En definitiva, estas estrategias contribuirían a apuntalar la pervivencia de la olivicultura tradicional en el valle de Huasco pero también podrían facilitar la construcción de un territorio ambiental, social y económicamente sostenible en la comuna, en el contexto de su región, teniendo en cuenta el valor de sus componentes naturales, sus problemas socioambientales y su patrimonio cultural, priorizando el papel de la población como factor de emprendimiento y las actividades agrícolas tradicionales, sin descuidar otras fuentes de riqueza como la minería, la industria, el comercio o el ecoturismo.

Agradecimientos: Este artículo es resultado de la financiación de la Asociación Universitaria Iberoamericana de Postgrado y del proyecto "Mi suelo es tu suelo" (OT-2015-3-40) del Departamento de Suelos y Recursos Naturales de la Universidad de Concepción (Chile).

Declaración responsable: Las/os autoras/es declaran que no existe ningún conflicto de interés en relación a la publicación de este artículo. Ambos autores han participado por igual en las tareas realizadas en la presente publicación. 


\section{Bibliografía}

ARDP, Agencia Regional de Desarrollo Productivo (2007). Atacama: Informe de caracterización. Copiapó: Instituto de Economía Aplicada Regional y Universidad Católica del Norte.

Arrancibia Araya, V., Zlatar Talaveras, J., Tapia Contreras, F., \& Mora González, M. (2013). Análisis Económico y Financiero para el Agronegocio de la Aceituna Sajada para el Valle del Huasco. La Serena: Instituto de Investigaciones Agropecuarias y Centro Regional de Investigación Intihuasi.

Bingham, E. T., Strong, J. E., Rhoads, J. D., \& Keren, R. (1985). An application of the MaasHoffman salinity response model for boron toxicity. Soil Science Society of America, 49, 672-674.

Casapia, E., Navarro, L., Noriega, R., Sáenz, M. (2005). Estrategias para el desarrollo del sector olivícola peruano. Lima: Ed. CENTRUM.

Castelleto, V., \& Bordoli, J. (2001). Proyecto olivicultura de la Compañía Minera del Pacifico S. A. In V Jornadas Olivícolas Nacionales (pp. 26-29). La Serena: Instituto de Investigaciones Agropecuarias.

Céspedes, R. (1998). La salinidad del suelo y del agua de riego y su relación con los cultivos. Proyecto: Validación de tecnología de riego en el valle del Huasco. La Serena: Instituto de Investigaciones Agropecuarias y Centro Regional de Investigación Intihuasi.

CELADE, Centro Latinoamericano y Caribeño de Demografía (2005). América Latina: urbanización y evolución de la población urbana, 1950-2000. Boletín Demográfico, 75, 1-311.

CIREN-CNR, Centro de Información de Recursos Naturales-Comisión Nacional de Riego (1997). Cartografía de la evapotranspiración provincial en Chile. Santiago de Chile: Centro de Información de Recursos Naturales.

Comité Nacional de Estadísticas Vitales. (2015). Estadísticas Vitales. Anuario 2013. Santiago de Chile: INE.

CONAMA, Comisión Nacional del Medio Ambiente (2004). Guía para el Establecimiento de las Normas Secundarias de Calidad Ambiental para Aguas Continentales Superficiales y Marinas. Santiago de Chile: CONAMA.

CONAMA, Comisión Nacional del Medio Ambiente (2007). Estrategia Nacional de Gestión Integrada de Cuencas Hidrográficas. Santiago de Chile: Ministerio de Medio Ambiente.

Cooper, T., Benavides, C., \& Sagredo, K. (2001). Productividad y añerismo: Siete años de investigación olivícola en el valle del Huasco. In V Jornadas Olivícolas Nacionales (pp. 18-21). La Serena: Instituto de Investigaciones Agropecuarias. 
Díaz Vial, C., Aviles Sommers, C., Nogueira Correa, A., \& Valdés Fabres, A. (1957). Estudio agrológico y de riego del valle del rio Huasco. Agricultura Técnica de Chile, 2, 355-411.

DIPLADE, División de Planificación y Desarrollo (2010). Identidades en Diálogo: Articulando Actores y Construyendo Realidades. Estudio Fortalecimiento de la Identidad Regional de Atacama. Santiago de Chile: Lom Editores.

Durán Pastrana, P. (1989). Estudio de Impacto ambiental de la planta de pellets de Huasco en la zona costera de Huasco, III Región (Memoria para obtener el título de Geógrafo, Pontificia Universidad Católica de Chile, Chile).

Elgueta, J. (2012). Consecuencias de la Gran Minería del Hierro en Huasco. Orígenes, desarrollo y evolución de los movimientos socio ambientales 1960-2012 (Proyecto de tesis para optar al grado de Magíster en Historia, Pontificia Universidad Católica de Valparaíso, Chile).

Gajardo, A. (2014). Etnicidad, reemergencia indígena y conflicto minero. El proyecto Pascua Lama, [el Estado] y el proceso de reetnificación de los Diaguitas del Huasco Alto, Chile. Anuari del conflicte social, 2014, 73-105.

Gajardo, R. (1995). La vegetación natural de Chile. Santiago de Chile: Editorial Universitaria.

Gómez Del Campo, M., Morales Sillero, A. M., Vita Serman, F., Rousseaux, M. C., \& Searles, P. (2010). El Olivar de los Valles áridos del Noroeste de Argentina (provincia de Catamarca, La Rioja y San Juan). Olivae, 114, 23-45.

Harvey, D. (2007). Breve historia del Neoliberalismo. Madrid: Akal.

Harvey, D. (2012). El enigma del Capital y las crisis del capitalismo. Madrid: Akal.

Ibacache González, A. (1987). Plagas y enfermedades del olivo en el valle del Huasco. Investigación y Progreso Agropecuario La Platina, 39, 22-23.

Ibacache González, A. (1988). Olivicultura en el valle del Huasco. Investigación y Progreso Agropecuario La Platina, 46, 17-20.

INIA, Instituto de Investigaciones Agropecuarias (1997). Estudio de validación de tecnología de riego en el valle del Huasco. Provincia de Huasco. III Región. Vallenar: INIA. Retrieved from http://bibliotecadigital.ciren.cl/handle/123456789/9675

INE, Instituto Nacional de Estadísticas (2007). Migración interna regional 1992-2002. Santiago de Chile: INE.

INE, Instituto Nacional de Estadísticas (2008). Población y migración interna. Características sociodemográficas 1997-2002. Santiago de Chile: INE. 
INE, Instituto Nacional de Estadísticas (2012). Población, País y Regiones: Actualización Población 2002-2012 y Proyecciones 2013-2020. Santiago de Chile: INE. Retrieved from http://www.ine.cl/canales/chile_estadistico/demografia_y_vitales/proyecciones2014/proye cciones-de-poblacion-2014.xlsx

INE, Instituto Nacional de Estadísticas (2015). Comunas: Población estimada al 30 de junio por sexo y edad simple 2002-2020 (Base de datos). Santiago de Chile: INE. Retrieved from http://www.ine.cl/docs/default-source/demogr\%C3\%A1ficas-yvitales/base_2002a2020_v3.xls?sfvrsn=6

Instituto Nacional de Normalización (1999). Norma Chilena Oficial Nch1333 of78. Modificada en 1987. Santiago de Chile: INN. Retrieved from

https://es.scribd.com/document/346197082/Nch1333-1978-Mod-1987-pdf

Martínez Barrera, L., \& Tapia Contreras, F. (2002). Riego del olivar en el valle del Huasco. La Serena: Instituto de Investigaciones Agropecuarias.

Millán, A. (1999). Historia de la minería del hierro en Chile. Santiago de Chile: Ed. Universitaria. Ministerio de Desarrollo Social (2012). Reporte Comunal: Comuna de Huasco. Primer Semestre. Santiago de Chile: Ministerio de Desarrollo Social. Retrieved from http://observatorio.ministeriodesarrollosocial.gob.cl/indicadores/pdf/comunal_general/atac ama/HUASCO.pdf

Ministerio de Desarrollo Social (2014). Reporte Comunal: Comuna de Huasco, Región de Atacama (Serie Informes Comunales, $n^{\circ}$ 1). Santiago de Chile: Ministerio de Desarrollo Social. Retrieved from

http://observatorio.ministeriodesarrollosocial.gob.cl/indicadores/pdf/comunal_general/atacama/ Huasco_2013.pdf

MINVU, Ministerio de Vivienda y Urbanismo (2009). Estado de la Planificación Urbana en Chile. Santiago de Chile: MINVU.

Montalegre, J., Aballay, E., Sanchez, S., Rivera, L., Fiore, N., \& Pino, A. M. (2009). Hongos y nematodos fitopatógenos asociados al sistema radical en uva de mesa en la III región de Chile. Aconex, 103, 5-9.

Mora, G. et al. (2013). Comercialización y gestión del agronegocio de la aceituna sajada. La Serena: Instituto de Investigaciones Agropecuarias y Centro Regional de Investigación Intihuasi.

Muntañola, J. (1996). Arquitectura como lugar. Barcelona: Ediciones UPC.

ODEPA, Oficina de Estudios y Políticas Agrarias. (2011). Propuesta de plan estratégico para la agricultura orgánica chilena 2010-2020. Santiago de Chile: Ministerio de Agricultura. 
Riveros, K., \& Riquelme, R. (2009). Estratigrafía neógena-cuaternaria de la cuenca del Río Huasco, norte de Chile: implicancias eustáticas, tectónicas y climáticas en el desarrollo de un sistema fluvial en el antearco externo de los Andes centrales. In XII Congreso Geológico chileno (pp. 1-9). Santiago de Chile: Universidad Católica del Norte.

Salazar Vergara, G., \& Pinto Vallejos, P. (1999-2002). Historia Contemporánea de Chile. Santiago de Chile: Lom Ediciones.

Salinas, B. (2007). Implicancias Territoriales del Conflicto Pascua Lama. Valle del Huasco, Región de Atacama (Memoria para optar al título profesional de Geógrafo, Universidad de Chile, Chile).

Sandoval Estrada, M. (2013). Proyecto de Responsabilidad Social Empresarial "Mi Suelo es tu Suelo". Componente 1 (Informe Ełapa de Diagnóstico sector Huasco bajo). Universidad de Concepción, Facultad de Agronomía.

San Juan, C. (2011). Capital social en el valle del Tránsito: transformación e impactos intangibles de la transnacional Barrick Gold Corporation en el Valle del Huasco: proyecto Pascua Lama (Tesis para optar al grado de Licenciada en Historia, Universidad de Chile, Chile).

Servicio Nacional de Geología y Minería. (2003). Mapa Geológico de Chile: versión digital (Mapas). Servicio Nacional de Geología y Minería. Retrieved from http://www.ipgp.fr/ dechabal/Geol-millon.pdf

Solano Asta-Buroaga, F. (1899). Diccionario Geográfico de la República de Chile. Santiago de Chile: F. A. Brockhaus.

Tapia, F., Astorga, M., Ibacache, A., Martínez, L., Sierra, C., Quiroz, C.,...Riveros, F. (2003). Manual del cultivo del olivo. Boletín del Instituto de Investigaciones Agropecuaria, 101, 1-128.

Tapia Contreras, F., \& Arrancibia Araya, V. (2006). Manejo del añerismo en olivo en el valle del Huasco. Boletín del Instituto de Investigaciones Agropecuaria, 40, 1-4.

Tapia Contreras, F., Ibacache Gonzalez, A. G., \& Arrancibia Araya, V. (2010). Comportamiento productivo e industrial de variedades de olivo de interés aceitero para Atacama. Tierra Adentro, julio-septiembre 2010, 34-37. Retrieved from

http://www2.inia.cl/medios/biblioteca/ta/NR37196.pdf

Torres Salinas, R. (2009). Conflictos por el agua en Chile: el gran capital contra las comunidades locales. Análisis comparativo de las cuencas de los ríos Huasco (desierto de Atacama) y Baker (patagonia austral). Espacio Abierto Cuaderno Venezolano de Sociología, 18(4), 695-708.

Urkidi, L. (2008). Movimientos anti-mineros: el caso de Pascua-Lama en Chile. Revista Iberoamericana de Economía Ecológica, 8, 63-77. 
Vargas Aceituno, F. (2014). El valle del Huasco, territorio dinámico entre la resistencia y el sacrificio. Análisis de la resistencia ciudadana frente a la planta faenadora de Agrosuper en Freirina (Tesis Magíster Geografía, Universidad de Chile, Chile).

Yáñez, N., \& Molina, R. (2008). La gran minería y los derechos indígenas en el norte de Chile. Santiago de Chile: Lom Ediciones. 